\title{
Exploring Critical Success Factors in Agile Analytics Projects
}

\author{
Mikhail Tsoy \\ Queen's University \\ mikhail.tsoy@queensu.ca
}

\author{
D. Sandy Staples \\ Queen's University \\ sandy.staples@queensu.ca
}

\begin{abstract}
Via updating Chow and Cao's list of success factors for agile projects, attributes of potential critical success factors (CSF's) for agile analytics projects were identified from the literature. Ten new attributes were added to Chow and Cao's original list. Seven new attributes from the general agile project literature address: risk appetite, team diversity and availability, engagement, project planning, shared goals, and methods uncertainty. Three attributes specific to analytics projects were added: data quality, model validation, and building customers' trust in model solution. The potential validity of the various CSF's and attributes was explored via data from case studies of two analytics projects that varied in deployment success. The more successful project was found to be stronger in almost all the factors than the failed project. The findings can help researchers and analytics practitioners understand the environmental conditions and project actions that can help get business value from their analytics initiatives.
\end{abstract}

\section{Introduction}

Efforts are growing rapidly in business to take advantage of the data they have access to. These initiatives are known by various names including business analytics, data warehousing projects, data mining, knowledge discovery in data, data science, big data, business intelligence, analytics 3.0. For this study, we refer to these types of projects as "Analytics Projects". We modify Chen et al's [9] definition of Business Intelligence and Analytics for the definition of analytics projects in our study - "An Analytics Project relates to the development and/or use of techniques, technologies, systems, practices, methodologies, and applications that analyze critical business data to help an enterprise better understand its business and market and make timely decisions".

While there are many success stories of analytics projects reported in the literature (e.g., [14]), it is also suggested that there are many challenges $[6,24,31,36$, 37]. How a project is selected, managed and transitioned into use (the product/output of the project) can have a significant impact on the value a business gets from the initiative [3]. This also applies to analytics projects $[2,38]$. Therefore, understanding more about how to effectively lead, support, and manage analytics projects can help organizations understand how to maximize the business value from initiatives.

Accordingly, the purpose of our study is to examine factors that may potentially affect the success of agile analytics projects. We specifically focus on agile analytics projects because an agile project approach is often suggested as being valuable for analytics projects $[16,18,21,31,36]$. Using an agile project life cycle can provide an experimental, iterative approach that can be an effective way to help resolve some of the uncertainty and allow project stakeholders to learn and evolve an effective solution. To our knowledge, critical success factors have not been specifically studied for agile analytics projects. The research question for our study is: "What are critical success factors for agile analytics projects?"

As outlined below in our literature review section, success factors have been examined for agile software projects. For example, Chow and Cao [10] compiled a comprehensive list of 12 critical success factors along with specific attributes for each success factor (36 in total). We use their list as a starting point, update it, and modify it for analytics-specific potential success factors. We use the attributes of the success factors to analyze data from case studies of two analytics projects that varied in successfulness.

This study makes contributions to both understanding the success factors for analytics projects and the success factors for agile projects generally. As noted by Chow and Cao, they did their study when agile practice was relatively immature and the respondents to their questionnaire were interested agile practitioners [10]. Agile practices have matured in the last decade so seeing if their results are consistent with today's body of knowledge is potentially valuable, as well as considering what possible success factors should be added or removed from their list to make it fit the nature of analytics projects. Our case-study approach provides an initial examination of the revised success framework and possibly insights into specific analytics projects.

Below we review the literature on success factors for agile projects to identify factors specific for agile analytics projects. We then explain our methodology and describe the findings. 


\section{Literature Review of Success Factors for Agile Analytics Projects}

Chow and Cao conducted a comprehensive review of suggested success factors reported in the agile literature for software development projects [10]. We use this as our starting point for developing an updated list of potential success factors for agile analytics projects. They initially identified 36 success attributes that potentially affect project success (success was defined via four dimensions - quality, scope, time, and cost). These attributes collapsed to twelve factors and were organized in five dimensions of factors (see Figure 1 from p. 964 Chow and Cao [10] below).

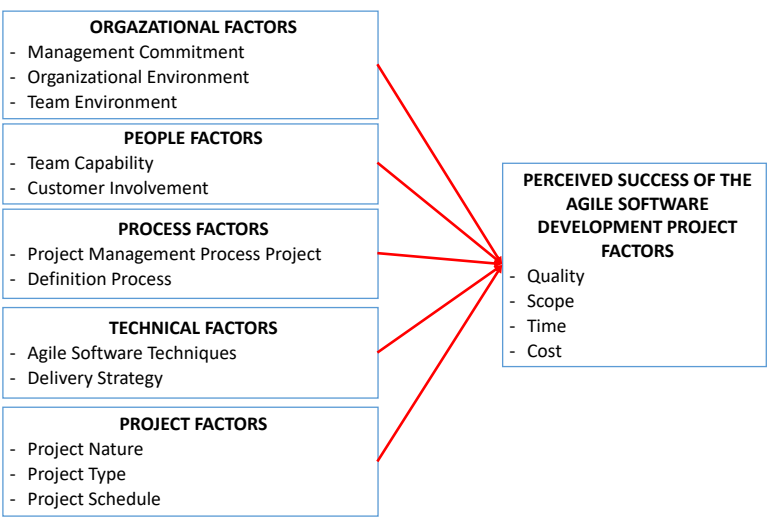

Figure 1: Chow and Cao's Model

Chow and Cao tested their model via a crosssectional questionnaire to members of the Agile Alliance [10]. Responses from 109 respondents suggested that six of the twelve success factors were linked to at least one dimension of success: delivery strategy, agile software engineering techniques, team capability, project management process, team environment, and customer involvement (the attributes of each of these are described more fully below). As the authors note, their results could have been biased by the lack of non-Agile advocates, the low response rate, and the relatively immature state of Agile methods at that time (leading them to conclude success factors may evolve and calling for future studies).

Since Chow and Cao's work was done over a decade ago, we conducted a literature review to update Chow and Cao's possible list of success factors and attributes, as well as search for analytic-specific project success research. A forward citation search was done on Chow and Cao's paper, as well as a general literature search in Google Scholar and the Proquest database (using the key words "agile", "analytics or business intelligence" and "project success factor".
While no studies were found that specifically examined analytics projects, several relevant studies were found that addressed other types of projects. Conforto et al. [12] focused on innovative projects like new development projects; all the other articles focused on software development projects. Close examination of the articles found that most of the success factors and attributes suggested were consistent with Chow and Cao's list $[1,12,15,20,22$, $27,30,32]$. However, this literature did suggest seven attributes that were not in Chow and Cao's [10] original list. These were: having multidisciplinary teams with appropriate diversity to match task complexity $[12,27]$, team dedication / time available exclusively for the project [12], goal clarity [12], engaging people [15], level of risk-taking willingness (i.e., risk appetite) $[32,34]$, technological uncertainty with respect to how to meet the requirements [1,32]; and the level of project planning [1].

The technical factors dimension deals with the delivery strategy and agile techniques specific to the nature of the project. The techniques that lead to success of software projects include: having welldefined coding standards up front, pursuing simple design, rigorous refactoring activities, the right amount of documentation, and correct integration testing. Since our study is focusing on analytics projects, we modified the attributes (by removing 3 software-specific attributes) and added 3 additional technical attributes found in the analytics literature, as these would be necessary for analytics projects. Practices to ensure strong data quality, model validation activities, and activities that build trust in the model solution with clients would all potentially be technical best practices $[6,16,36]$.

Table 1 below summarizes the success factors and attributes in the original Chow and Cao research, and, in the right-column, presents the list of revised attributes. The attributes that are new from the updated agile literature and analytics literature are bolded.

\section{Methodology}

This study uses a case-based research strategy to study two projects throughout their life cycle. This strategy is appropriate as it fits our research questions and allows us to examine contemporary events that have complex contextual conditions, as almost all projects do. Within any project, there are many practices and factors that interact with the setting of the project. For example, the stakeholders involved and their power within the organization could affect the outcomes, the core team skills and their interaction patterns could affect productivity, and the organizational (or departmental) culture could affect 
the support received for the project and the role of project leadership.

A multiple-case design is appropriate also for the following reasons. The case study approach allows us to study critical success factors in "a natural setting, learn about state of the art, and generate theories from practice" [5:370]. The case study approach also allows us to understand better the "nature and complexity of processes taking place" (p. 370). Therefore, a small number of cases may be able to provide insights, and the multiple-case designs allow for "cross-case analysis and theory extension" [5:373].

As much as possible, Yin's [39] suggestions for establishing reliability and validity, and analyzing case study evidence was followed (e.g., developing a detailed case study protocol, case study database, interview script, coding and pattern matching, etc.). Our unit of analysis is the project.

\subsection{Sample and Data Collection}

Theoretical sampling logic was used to select two analytics projects that had variation in project success. There are potentially many dimensions of success. We chose to use business implementation / deployment as the prime success indicator, as that reflects a significant aspect of realizing business value. Data collection for each project was done by interviewing

Table 1: Adapted Agile Analytics Success Factors and Attributes

\begin{tabular}{|c|c|c|}
\hline $\begin{array}{l}\text { Success Dimension } \\
\text { and Success Factor }\end{array}$ & Chow and Cao's Attributes & $\begin{array}{l}\text { Attributes For Agile Analytics Success (new } \\
\text { attributes bolded) }\end{array}$ \\
\hline $\begin{array}{l}\text { Organizational } \\
\text { Factors: } \\
\text { - Management } \\
\text { Commitment }\end{array}$ & $\begin{array}{l}\text { Strong executive support; Committed sponsor } \\
\text { or manager }\end{array}$ & $\begin{array}{l}\text { Strong executive support; Committed sponsor or } \\
\text { manager }\end{array}$ \\
\hline $\begin{array}{l}\text { - Organizational } \\
\text { Environment }\end{array}$ & $\begin{array}{l}\text { Cooperative organizational culture; Universal } \\
\text { acceptance of agile methodology; Reward } \\
\text { system appropriate for agile teams; Facility } \\
\text { with proper agile-style work environment }\end{array}$ & $\begin{array}{l}\text { A willingness to take on risks; Cooperative } \\
\text { organizational culture; Universal acceptance of agile } \\
\text { methodology; Reward system appropriate for agile } \\
\text { teams; Facility with proper agile-style work } \\
\text { environment }\end{array}$ \\
\hline - Team Environment & $\begin{array}{l}\text { Collocation of team; Small team; Coherent, } \\
\text { self-organizing teamwork; projects without } \\
\text { multiple independent teams; Managers } \\
\text { knowledgeable in agile processes }\end{array}$ & $\begin{array}{l}\text { Collocation of team; Small team; Coherent, self- } \\
\text { organizing teamwork; projects without multiple } \\
\text { independent teams; Managers knowledgeable in } \\
\text { agile processes }\end{array}$ \\
\hline $\begin{array}{l}\text { People Factors: } \\
\text { - Team Capability }\end{array}$ & $\begin{array}{l}\text { Team with high competence and expertise; } \\
\text { Adaptive management styles; Team members } \\
\text { with great motivation; Appropriate technical } \\
\text { training to team }\end{array}$ & $\begin{array}{l}\text { Having the appropriate diversity to match task } \\
\text { complexity; Team dedication / time availability } \\
\text { exclusively for the project; Engaging people; } \\
\text { Team with high competence and expertise; Adaptive } \\
\text { Management Styles; Team members with great } \\
\text { motivation; Appropriate technical training to team }\end{array}$ \\
\hline $\begin{array}{l}\text { - Customer } \\
\text { Involvement }\end{array}$ & $\begin{array}{l}\text { Good customer relationship; Strong customer } \\
\text { commitment; Customer having full authority }\end{array}$ & $\begin{array}{l}\text { Good customer relationship; Strong customer } \\
\text { commitment; Customer having full authority }\end{array}$ \\
\hline $\begin{array}{l}\text { Process Factors: } \\
\text { - Project Management } \\
\text { Process }\end{array}$ & $\begin{array}{l}\text { Agile-oriented requirement management, } \\
\text { project management, and configuration } \\
\text { management processes; Good process } \\
\text { tracking mechanism; Strong communications } \\
\text { focus with daily face-to-face meetings; } \\
\text { Honoring regular work schedules }\end{array}$ & $\begin{array}{l}\text { Good project planning; Agile-oriented requirement } \\
\text { management, project management, and configuration } \\
\text { management processes; Good process tracking } \\
\text { mechanism; Strong communications focus with daily } \\
\text { face-to-face meetings; Honoring regular work } \\
\text { schedules; }\end{array}$ \\
\hline $\begin{array}{l}\text { - Project Definition } \\
\text { Process }\end{array}$ & Up-front risk analysis; Up-front cost analysis & $\begin{array}{l}\text { Establishing clear goals; Up-front risk analysis; } \\
\text { Up-front cost analysis }\end{array}$ \\
\hline $\begin{array}{l}\text { Technical Factors: } \\
\text { - Agile Software / } \\
\text { Analytics Techniques }\end{array}$ & $\begin{array}{l}\text { Defined coding standards; Pursing simple } \\
\text { design; Rigorous refactoring; Appropriate } \\
\text { documentation; Correct integration testing }\end{array}$ & $\begin{array}{l}\text { Ensure high data quality; Model validation } \\
\text { activities; Build customer's trust in model } \\
\text { solution; Pursing simple design; Appropriate } \\
\text { documentation }\end{array}$ \\
\hline - Delivery Strategy & $\begin{array}{l}\text { Regular delivery of customer functionality; } \\
\text { Delivering most important features first }\end{array}$ & $\begin{array}{l}\text { Regular delivery of customer functionality; } \\
\text { Delivering most important features first }\end{array}$ \\
\hline $\begin{array}{l}\text { Project Factors: } \\
\text { - Project Nature }\end{array}$ & Project nature being non-life-critical & Project nature being non-life-critical \\
\hline - Project Type & Variable scope with emergent requirements & $\begin{array}{l}\text { Technological uncertainty with respect to how to } \\
\text { meet requirements; Variable scope with emergent } \\
\text { requirements }\end{array}$ \\
\hline - Project Schedule & Dynamic, accelerated schedule & Dynamic, accelerated schedule \\
\hline
\end{tabular}


key project stakeholders: members of the project team (all if possible), the project leadership (e.g., sponsors, department heads, senior executives affected by the project, people involved in project selection and approval), and the project clients (who potentially ended up using the outcome of the project). Interviews lasted about 1.5 hours each, and 20 interviews were completed in total for the two projects. Both projects were being conducted in the same large financial institution, but in different divisions and by different project teams.

The Clover project was successful in meeting the business requirements, although it was slightly later than originally planned (approximately 2 weeks). The model was successfully validated and is currently being tested in the production environment (i.e., a proof of concept (POC) of the effectiveness of the model). Initial results are exceeding expectations so it is expected the model will be fully implemented after the 6-month POC phase is over. The Pars project was less successful ${ }^{1}$. Project Pars finished model development several months later than initially planned. At that point, validation of the model by the business side proceeded and it was determined that the model did not meet business requirements. The model was therefore not deployed, and the project was abandoned.

Several characteristics of the two projects are presented in Table 2. This information was gathered during the interview with each team member. Members of the Clover project had higher beliefs in their team ability, their satisfaction, and their psychological safety. The Pars project had considerably higher uncertainty regarding both requirements and methods to meet the requirements. The Clover project team and executives had a clear understanding of the requirements (with some uncertainty about how to reach their objectives).

Table 2: Characteristics of the Projects

\begin{tabular}{|l|c|c|}
\hline Indicator & $\begin{array}{c}\text { Project } \\
\text { Pars }\end{array}$ & $\begin{array}{c}\text { Project } \\
\text { Clover }\end{array}$ \\
\hline $\begin{array}{l}\text { Psychological safety } \\
\text { within the team }{ }^{13}\end{array}$ & 5.2 & 6.6 \\
\hline Team Potency ${ }^{4}$ & 5.2 & 6.2 \\
\hline $\begin{array}{l}\text { Satisfaction with the } \\
\text { Team }\end{array}$ & 5.0 & 6.7 \\
\hline Team Commitment $^{1}$ & 6 & 6.7 \\
\hline $\begin{array}{l}\text { Uncertainty of } \\
\text { requirements }\end{array}$ & 6 & 1 \\
\hline Uncertainty of methods ${ }^{2}$ & 6 & 2.6 \\
\hline
\end{tabular}

1. The average score of team members measured on a 1 (low) to 7 (high) scale

2. The average score of team members measured on a 1 (low) to 10 (high uncertainty) scale

\footnotetext{
${ }^{1}$ Project names are disguised to protect the confidentiality of the participating organizations.
}

3.Team psychological safety was measured with Edmondson's [17] 7-item scale. (Cronbach alpha $=0.73$ )

4. Team potency was measured with Guzzo et al's [19] 8item scale. $($ Cronbach alpha $=0.77)$

\subsection{Data analysis}

As described above, we combined the success/failure factors from Chow and Cao [10] and the literature found in the period after its publication. We then coded the interviews using the compiled list of factors and attributes as the guide. We organized the attributes into twelve success factors as per Chow and Cao [10]. When we compared the two cases of analytics projects that adopted agile PM methods, we observed a number of differences and similarities.

\section{Findings}

The findings below are organized by the five dimensions, and then each success factor is reviewed. The attributes we saw in the projects are reviewed for each factor. At the end of each section, we offer a comparison of the two projects, with respect to the CSF.

\subsection{Organizational factors}

4.1.1 Management Commitment. Strong executive support: Project Clover had very strong executive support. Project members stated that they had the attention from their executives during the project. Project Clover had a rigorous project selection process and regular update meetings with leadership. In contrast, Project Pars had difficulties in terms of getting executives to attend regular product demo meetings.

Committed sponsor or manager: Project Pars experienced change in the product owner from the business side with about a month-long gap before another product owner was appointed. Furthermore, once a new product owner was appointed, he/she attempted to "reevaluate" the project. Furthermore, project Pars team members cited the previous product owner's busyness as a reason for appointing a representative/SME to be present in his/her stead. Also, Project Pars faced resistance towards the use of Agile processes such as daily stand-up meetings and the attendance of business representatives:

Business side, they were a little bit not used to it (Agile processes), and even daily standups for them were a big thing. Like, "Oh, why do I need to go there daily and give updates?" They're not used to it. (Project Pars) 
This data suggests management commitment was stronger for project Clover than Pars.

4.1.2 Organizational Environment. Cooperative Organizational Culture and and Facility with Proper Agile-Style Work Environment: While both projects were being done by the same company, they were being run in different departments. This implies there was some shared organizational culture; however, we did see that the departmental cultures were somewhat different. The department project Clover was in had shared workspaces, community areas, and social areas. This was done to facilitate collaboration, knowledge sharing and create a fluid structure. Project Pars' department structure seemed to be more traditional with cubicle work areas. This implies that perhaps the organizational environment at Pars' unit was less collaborative. In support of this, the team measures of psychological safety and team potency in Table 1 show a sizable difference on both factors between two projects: Project Clover performs higher on both constructs.

Willingness to take on risks: Project Pars demonstrated a high level of willingness to take risk as the project they pursued was more exploratory in the nature which was acknowledged by management before the start of the project:

Many shareholders initially came, only [one] guy had some idea but as we worked in the project, we figured out maybe it's way too hard, not solvable. ... Everyone agreed so ... let's see what we can get. At the end they were not satisfied but at the same time they were like, okay, we expected that. ... You're allowed to fail. (Project Pars)

Iivary and Iivary [22] theorized that the level of entrepreneurship and level of willingness to take risks are indicators of "the flexibility and adaptability of the project, and the empowerment of the project team to cope with change requests" (p. 469). Further the authors expect that these variables have positive influence on project success. At the same time, Project Clover demonstrated lower levels of willingness to take risks as the type of project pursued, and feasibility was carefully assessed in their selection process. They had a track record of successful projects, so the Clover project built on this experience and knowledge, and some of the project team had worked on similar projects.

That can be explained by the nature of the projects each of the departments usually pursue: Project Pars team usually worked on innovative, experimental projects and Project Clover team aimed to pursue projects that fit with rigorous selection criteria that aimed to maximize the value and impact of each project:

One, does this align to the \{company's strategy? Second, do we have the data for it? Third, what is the impact?
Fourth, is it feasible? Five, do we have the resources? Then, you can basically rank order everything and say: Okay, if I take the \{a number of projects\}, I check all the boxes, and I can actually do it. (Project Clover)

Further the difference in the willingness to take risks between to projects can be observed on how each project scored in terms of uncertainty of requirements or methods in Table 1. We can see that levels of uncertainty faced by Project Pars were relatively high when compared to those of Project Clover.

From the information processing view of organizations, organizational performance depends on the fit between context and structure $[8,26]$ Information processing capabilities should fit the level of uncertainty faced by an organization. Consequently, we posit that willingness to take risks should be matched by the appropriate levels of information processing capability of the project team and organization for projects to succeed. Similarly, Jun et al. [23] discovered that high information processing capability stems from internal integration and user participation. Thus, it appears that while Project Clover had an appropriate information processing capability that matched its willingness to take risks, Project Pars might have underestimated the need for higher levels of information processing capability required by the type of projects they pursued.

Universal Acceptance of Agile Methodology: Project Pars faced resistance from a product owner:

Personally, I'm not a fan of these innovative ways of doing, this process. I know this agile, scrum master is coming from the IT process. They find it extremely efficient, but to me, in the business world, I don't find it to be that good." (Project Pars)

That resulted in the "dilution" of Agile practices such as daily stand-ups and led to reduced frequency of demo meetings. On the other hand, Project Clover experienced more acceptance even with project members who did not have prior Agile project experience. This relates to the selection process described before: the department selected projects from the list of possibilities partially based on the business units desire to both conduct the project and learn the Agile processes that the team used.

The findings above are similar to the observations by Boehm and Turner [7]: we observed cases of individual resistance towards the change within teams and department. Also, we can see that such resistance can be reduced with experience and an established track record of projects.

Reward system appropriate for agile teams: While our data does not contain evidence specifically about reward systems, we assume formal reward structures were more or less the same for each project. However, we observed that Project Clover team came together to 
celebrate project closing, while Project Pars simply dissolved once the required tasks were completed.

While the Pars project demonstrated a higher willingness to take on risk, the other evidence suggests the organizational environment for Clover was more conducive to a successful agile approach.

4.1.3 Team Environment. Collocation of whole team: Project Pars had only three of the data scientists collocated in the same office space (i.e., only part of the project team and none of the business). On the other hand, Project Clover aimed to have most of project team from both business and analytics team members collocated on the same floor, and most were in a shared workspace. A member of the Project Clover team cited team collocation as one of the most effective practices when reflecting on project performance.

One of my most favorite projects \{because of t team engagement and energy level and collaboration. I think everyone was there to learn and collaborate. When one person has a problem, they all got together and tried to solve the problem. Part of it is the co-location. ...We actually found a way to relocate ourselves into one room. That really improved the communication level, and everyone was very excited about the results, the things that they do. (Project Clover)

Small team size: Both projects had teams smaller than 10 people, meeting typical expectations for an effective agile team size.

Cohererent, self-organizing teamwork: Both teams had a fair bit of autonomy to make decisions regarding the direction that project takes:

There was a lot of, I would say, power or confidence in the team to make ... decisions as opposed to stopping and saying "Oh no, we're going down another path. Do I need a permission before we do this?" (Project Pars)

A project without multiple independent teams: Both project teams consisted of people from two or more departments. That is usually the case with analytics projects [31], as they typically involve business and analytics components. However, as both projects were small in size, each had only one project team.

Managers knowledgeable in agile processes: Both managers of the project had previous experience with agile processes.

On balance, both projects had an effective team environment, with Clover being somewhat stronger due to the collocation.

\subsection{People Factors}

4.2.1 Team Capability. Appropriate diversity of skills and knowledge: Typical analytics projects involves stakeholders from the business and analytics sides working together [31]. That was the case for both projects: each project had stakeholders from multiple business departments and one or more analytics stakeholders (e.g., data engineers and data scientists).

Team with high competence and expertise: Similarly, both project's team members appeared to have expertise in their respective tasks with multiple years of work experience in some cases. However, Project Clover team had experience in conducting similar type of projects while the Project Pars team pursued a more exploratory, novel type of project.

Time dedicated exclusively for the project: Conforto et al. [12] found that a successful agile project requires somewhere between $76 \%$ to full time (>90\%) of time allocated to work on the project. In Project Clover, we observed that most of the project team members were collocated. There were some members who started with part time allocation of $25 \%$, which is what Conforto et al. [12] found to be the case in traditional, plan-driven approach. However, that proportion of allocated time changed for Project Clover team members as the project progressed and required more of their time (depending on their role):

Initially in the first sprints some people needed to be a certain percentage of the time in the \{project team space\} but in the end for the final sprints, for example, I needed to be $100 \%$ for these last sprints so that planning of having the necessary people full time if that was needed, or partial time at the initial stages was appropriate I would say. (Project Clover)

We observed the opposite in the Project Pars as time increased for the analytics experts on the team while others stopped participation in such Agile practices as daily stand-ups and product demos (i.e., withdrew). It was clear that more dedicated resources were devoted to project Clover than project Pars.

Adaptive Management Styles: The analytics manager of the Clover team was very knowledgeable about agile techniques and processes and strongly supported this approach, as did his executive VP. The same level of support was not evident with the analytics department running the Pars project, although the department manager did seem to have an innovative and adaptive mindset.

Team members with great motivation: Team members for both projects had relatively high commitment and confidence in their team (see Table 2).

Overall, both teams had fairly strong team capability, with Clover being somewhat stronger.

4.2.2 Customer involvement. Good customer relationship, strong customer commitment and presence: Project Clover enjoyed strong customer commitment and presence as the department usually selects a limited 
number of projects out of list of interested customers. Thus, customers are motivated to participate, committed to the project, and were willing to provide competent people to be dedicated to the project. Project Pars faced less customer commitment and presence due to exploratory nature of the project. Customers were less optimistic of potential project success (Please refer to quote by Project Pars in 4.1.2 Organizational Environment). Our data did not allow us to explore the level of authority customers had.

\subsection{Process Factors}

4.3.1 Project Management Process. Agile-oriented processes: The Clover project had run several previous projects with an agile approach, invested in training, had an outside consultant available for coaching, and had a full-time project manager/scrum master on the team. The manager of the Pars project was quite supportive of an agile approach; however, the support given to the team to learn the approach was very limited. A part-time scrum master was added to the project part-way through and some team members described agile approach used in the project as "pseudo-agile \{with\} Scrum flavor" or "a pretty loose model \{of Agile\}".

Effective stakeholder engagement: In project Pars one of the SME's (Subject Matter Expert, customer representative in our case) was involved in a number of projects and had more extensive adherence to agile processes. Another SME had extensive experience working in more traditional PM methods and preferred that approach. The participation of the second Product Owner could be described as ad-hoc and sporadic depending on need and availability.

Stakeholder commitment varied in Project Clover, during the project lifecycle depending on the commitment requirement (Please refer to the quote from 4.2.1 Team Capability). However, for the most part, Project Clover SMEs were collocated with the rest of the team and participated in daily stand-ups. The senior management of the Clover project was also more engaged with regular updates and project involvement.

Effective progress tracking mechanism: The Project Clover team had stronger monitoring and controlling in place. They used an electronic team board, daily standup meetings, weekly management updates, and reviews and retrospectives at the end of each of their 3-week iterations. While the Pars team also used a team board, the other typical agile mechanisms were more applied in more ad-hoc fashion and declined in use over time.

Strong communication with F2F meetings: Project Clover team had more opportunities to build upon faceto-face communication due to team collocation and a daily stand-up practice. On the other hand, Project Pars had to further "dilute" its Agile practices and stopped conducting daily stand-ups due to the resistance from participants. Although, Project Pars team continued to communicate with stakeholders via phone calls, it relied less on face-to-face communication compared to Project Clover. The Clover team continued conducting daily stand-ups using voice calls and virtual screen sharing tools for members that were not able to be physically present at the meeting.

Effective project planning (level of project planning,): Building on the need for effective project planning discussed in Chow and Cao [10], Ahimbisibwe et al. [1] suggest that the level of project planning influences consequent project performance. Our findings illustrate the differences in planning for the project and overall project portfolio for the department. Project Clover deliberately planned to execute a certain number of projects based on the department capacity to complete projects in a given time period. However, we did not find similar rigor in project selection in case of Project Pars. That can somewhat be explained by the nature of projects carried out by each of the departments: Project Clover aims to deliver maximum business value given several key criteria and Project Pars tends to pursue innovative and exploratory projects with less certainty regarding requirements and methods. The Clover project also had stronger project and iteration planning, using sprint zero as a feasibility and detailed planning stage, followed by a strong kickoff with the project community.

Overall, the evidence suggests Project Clover had stronger PM processes than the Pars project.

4.3.2 Project Definition Process. Goal clarity: Team members in the Project Clover team had a clear understanding of what the ultimate goal being pursued by the project was. Project Pars team demonstrated less clarity regarding the project goal:

Well, I have an idea, but it's my own idea. I don't know if this is the idea of the team... (Project Pars)

Risk and cost analysis: Risk analysis was done, and a business case was developed as part of the selection process for the Clover project. This material was further developed once iteration zero of the project commenced. There was little evidence of this sort of analysis for the Pars project.

Overall, the Clover project had a stronger process for defining the project.

\subsection{Technical Factors}

4.4.1 Agile Analytics Techniques. Right amount of documentation: One of the Agile principles calls for "working software (functional output) over documentation [4]. However, that does not eliminate the 
need to keep track of the learning that occurs during lifecycle of the project. Both project teams documented and shared their project experience and technical documentation via online medium provided by the company. However, we did not have access to the documentation produced by either of the project teams.

Data quality: Data quality was referred to as one of the main challenges by the majority of team members of both project teams. Usually, the early part of the projects was spent on finding and understanding the available data in order to prepared it for modeling:

Data always has some quality issues so how you figure it out. (Project Pars)

However, the way each project team dealt with data quality challenges was different. Project Clover planned up-front a significant portion of project time to explore and test the data. That allowed them to minimize data quality related project delays and they managed to finish project largely on-time. On the other hand, Project Pars experienced significant project delays due to unanticipated data quality issues.

Model validation activities: Both project teams conducted model validation activities that appeared to be standard and expected in their organization.

Building clients' trust in the data solution: One of the challenges faced by analytics is whether the data solution will be used by the customers. This can be caused by a lack of understanding by the business side about how the data model was developed and how it operates. Thus, it is important to involve customers in both development of the model and start communication processes with the client early in the project timeline. Project Clover team did this well and increased the amount of communication with the client before the final product was shipped. That ensured that clients became increasingly familiar with the project output, implications for deployment, and that it fit expectations:

Before that we would meet with the business once a week but then towards the end... I would say the sprint is three weeks. The first week of that last sprint probably twice a week instead of just one time. Then second week was maybe three times a week and the last week it was every day. ... Those meetings don't have to be two hours. It could be ten minutes here, a five-minute phone call; at least talking to them. \{Getting them ready to know what's coming?\} Exactly. (Project Clover)

Project Pars found it challenging to involve customers and get leadership attention for regular demo meetings, and the relationship between the business and analytics team was not as strong.

Overall, the Clover project demonstrated superior analytics techniques due to the way they built client understanding of the solution and handled data quality.
4.4.2 Delivery Strategy. Regular delivery of functionality to the customer: Neither of the projects had regular delivery of functional features to the customer. That can be explained by the nature of the analytics projects pursued by both project teams as the first few sprints are spent on understanding data and solving potential data issues. There was no opportunity to deliver increment working products, as one final model was delivered after several sprints (Please refer to the quote from data quality above). Thus, both analytics projects aimed to conduct product demo meetings in the latter part of the project, as well as routinely keep the customer aware of progress. That does not reject the importance of delivery strategy discovered by Chow and Cao [10] for agile projects as the importance of delivery strategy depends upon the nature of the project to deliver incrementally to the customer. Thus, it depends on the type of project pursued by the agile analytics team.

Delivering the most important features first: For our analytics projects to be successful deployed, the model had to be validated and accepted. Pars' model failed their validation because they had not met a key requirement. Therefore, we rate Pars weaker on understanding customers' requirements. The Clover team seemed to fully understand what things were most important for their customers and delivered these.

\subsection{Project Factors}

4.5.1 Project Nature. Non-life critical project nature: The ability to take on risks and pursue projects with higher uncertainty are related to the nature of the project. Both projects in our study aimed to improve upon existing products. In both cases, partial implementation with extended testing against existing product or solution was planned. That fits Chow and Cao's [10] non-life critical project nature description.

4.5.2 Project Type. Variable scope with emergent requirements and technological uncertainty: Project Pars faced greater uncertainty in terms of requirements and methods to achieve them (including technological uncertainty) due to the exploratory nature of the project. Project Clover faced lower levels of uncertainty due to the previous experience in similar projects and their careful selection process.

4.5.3 Project Schedule. Dynamic schedule. The Clover project had a clear time-boxed approach and it was an aggressive schedule (90 days) for the team to work through the data uncertainties and then develop a valid model. While there was a timeline in place for the Pars project, it had to be pushed back more than once, and in the early stages of this project, the timing seemed to simply drift, as the project became isolated. 


\section{Discussion}

Table 3 contains a summary of how strong the projects were on the twelve success factors. This assessment is based on analyses of the various attributes for each of the two cases, as discussed above. A quick glance at Table 3 shows that the Clover project was either equal or stronger than the Pars project on almost all success factors. Since the Clover project was more successful in terms of deployment (i.e., potentially delivering business value), the findings provide preliminary support for the importance of the success factors.

Table 3: Success factors in the Projects

\begin{tabular}{|c|c|c|c|}
\hline Dimension & Factors & $\begin{array}{c}\text { Project } \\
\text { Clover }\end{array}$ & $\begin{array}{c}\text { Project } \\
\text { Pars }\end{array}$ \\
\hline \multirow{4}{*}{$\begin{array}{c}\text { Organiza- } \\
\text { tional }\end{array}$} & $\begin{array}{c}\text { Management } \\
\text { Commitment }\end{array}$ & ++1 & - \\
\cline { 2 - 4 } & $\begin{array}{c}\text { Organizational } \\
\text { Environment }\end{array}$ & + & - \\
\cline { 2 - 4 } People & Team Environment & ++ & + \\
\cline { 2 - 4 } & Team Capability & ++ & + \\
\hline \multirow{4}{*}{ Process } & $\begin{array}{c}\text { Customer } \\
\text { Involvement }\end{array}$ & ++ & - \\
\cline { 2 - 4 } & $\begin{array}{c}\text { Project Management } \\
\text { Process }\end{array}$ & ++ & - \\
\hline \multirow{3}{*}{ Technical } & $\begin{array}{c}\text { Project Definition } \\
\text { Process }\end{array}$ & ++ & - \\
\cline { 2 - 4 } & $\begin{array}{c}\text { Agile Analytics } \\
\text { Techniques }\end{array}$ & ++ & - \\
\hline \multirow{2}{*}{ Project } & Delivery Strategy & - & -- \\
\cline { 2 - 4 } & Project Nature & + & + \\
\cline { 2 - 4 } & Project Type & + & ++ \\
\hline
\end{tabular}

1. ++ is for "very strong", + is "moderately strong", - is "moderately weak", and - - is "very weak"

The pattern illustrated in Table 3 supports the importance of all the CSF's. All projects are complex with interrelated aspects so undoubtedly the factors are interdependent. Our data does not allow us to empirically determine which factors are more important than others. Doing this with a larger sample would be valuable future work, and could be helpful to guide practice. However, based on what we observed in these projects, we would offer the following.

We suggest organizational factors such as management commitment, organizational and team environment are critical foundations on which project success is built. Management commitment ensures closer customer involvement, resources, and more rigorous project and project team selection. Further, an organization should build a cooperative culture and match willingness to risk in projects with the capacity to manage those risks. This enhances the agile fit.

Solid process factors appear to enhance effective stakeholder and customer engagement. Face-to-face interaction potentially enables tighter communication and coordination within the project team. This should enhance clients' acceptance and trust in the final project output. Therefore, an appropriate team environment is important to create.

The nature of the project the importance of each factor may vary. For our analytics projects, data quality was not surprisingly an important attribute of the agile analytics technique success factor. However, the delivery strategy that follows agile principles of delivering a potentially shippable outcome at the end of each sprint appeared to be infeasible for our projects. We expect that importance of each of those factors will depend on the nature of the agile analytics project (i.e., an infrastructure analytics project may be able to deliver product increments, whereas a data science project that creates one model cannot).

To summarize, in this study we explored critical success factors for agile analytics projects. We updated the findings from Chow and Cao (2008) by searching for additional attributes that were studied and theorized since publication of the manuscript. We added 7 agile attributes, as well as 3 attributes specific to analytics projects. We found preliminary support for the revised model via our case studies. However, we studied two analytics projects in the same organization. Future research is needed to validate and test relationships among the factors and dimensions of project success. Comparing these findings to traditional projects could also useful in building our understanding of analytic project success. We hope that future research will be undertaken to further understand success factors for analytics projects and investigate the interdependencies.

\section{References}

[1] Ahimbisibwe, A., R.Y. Cavana, and U. Daellenbach, “A contingency fit model of critical success factors for software development projects: A comparison of agile and traditional plan-based methodologies", Journal of Enterprise

Information Management 28(1), 2015, pp. 7-33.

[2] Alby, T., "Project Management in Data Science", 2017. https://www.projectmanagement.com/articles/398882/Project -Management-in-Data-Science

[3] Badewi, A., "The impact of project management (PM) and benefits management $(\mathrm{BM})$ practices on project success: Towards developing a project benefits governance framework", International Journal of Project Management 34(4), 2016, pp. 761-778.

[4] Beck, K., M. Beedle, A. Cockburn, et al., Manifesto for agile software development. February 9, 2011, 2001.

[5] Benbasat, I., D.K. Goldstein, and M. Mead, "The case research strategy in studies of information systems", MIS quarterly, 1987, pp. 369-386.

[6] Bishop, D., "Don't forget the data", (2011).

[7] Boehm, B., and R. Turner, "Management Challenges to Implementing Agile Processes in Traditional Development Organizations", IEEE Software 22(5), 2005, pp. 30-39. 
[8] Burns, T., and G.M. Stalker, "The management of innovation. London", Tavistock Publishing. Cited in Hurley, $R F$ and Hult, GTM (1998). Innovation, Market Orientation, and Organisational Learning: An Integration and Empirical Examination. Journal of Marketing 62, 1961, pp. 42-54.

[9] Chen, H., R.H. Chiang, and V.C. Storey, "Business intelligence and analytics: From big data to big impact.", MIS quarterly 36(4), 2012.

[10] Chow, T., and D.-B. Cao, "A survey study of critical success factors in agile software projects", Journal of Systems and Software 81(6), 2008, pp. 961-971.

[11] Cohn, M., and D. Ford, "Introducing an agile process to an organization [software development]", Computer 36(6), 2003, pp. 74-78.

[12] Conforto, E.C., F. Salum, D.C. Amaral, S.L. da Silva, and L.F.M. de Almeida, "Can Agile Project Management Be Adopted by Industries Other than Software Development?", Project Management Journal 45(3), 2014, pp. 21-34. [13] Conforto, E.C., F. Salum, D.C. Amaral, S.L. da Silva, and L.F.M. de Almeida, "Can Agile Project Management be Adopted by Industries Other than Software Development?", Project Management Journal 45(3), 2014, pp. 21-34.

[14] Davenport, T.H., "Analytics 3.0", Harvard Business Review 91(12), 2013, pp. 64-72.

[15] Dikert, K., M. Paasivaara, and C. Lassenius,

"Challenges and success factors for large-scale agile transformations: A systematic literature review", Journal of Systems and Software 119, 2016, pp. 87-108.

[16] Eckerson, W., Secrets of analytical leaders: Insights from information insiders, Technics Publications, Westfield, NJ, 2012.

[17] Edmondson, A., "Psychological safety and learning behavior in work teams", Administrative science quarterly 44(2), 1999, pp. 350-383.

[18] Gemino, A., B.H. Reich, and C. Sauer, "A temporal model of information technology project performance", Journal of Management Information Systems 24(3), 2007, pp. 9-44.

[19] Guzzo, R.A., P.R. Yost, R.J. Campbell, and G.P. Shea,

"Potency in groups: Articulating a construct", British journal of social psychology 32(1), 1993, pp. 87-106.

[20] Hoda, R., J. Noble, and S. Marshall, "The impact of inadequate customer collaboration on self-organizing Agile teams", Information and Software Technology 53(5), 2011, pp. 521-534.

[21] Howell, D., C. Windahl, and R. Seidel, “A project contingency framework based on uncertainty and its consequences", International Journal of Project Management 28(3), 2010, pp. 256-264.

[22] Iivari, J., and N. Iivari, "The relationship between organizational culture and the deployment of agile methods", Information and Software Technology 53(5), 2011, pp. 509520.

[23] Jun, L., W. Qiuzhen, and M. Qingguo, "The effects of project uncertainty and risk management on IS development project performance: A vendor perspective", International Journal of Project Management 29(7), 2011, pp. 923-933.
[24] Kaisler, S., F. Armour, J.A. Espinosa, and W. Money, "Big Data: Issues and Challenges Moving Forward", 2013 46th Hawaii International Conference on System Sciences, (2013), 995-1004.

[25] Larman, C., Agile and iterative development: a manager's guide, Addison-Wesley Professional, 2004.

[26] Lawrence, P.R., and J.W. Lorsch, "Differentiation and integration in complex organizations", Administrative science quarterly, 1967, pp. 1-47.

[27] Lee, G., and W. Xia, "Toward agile: an integrated analysis of quantitative and qualitative field data on software development agility", Mis Quarterly 34(1), 2010, pp. 87114.

[28] Lee, and Xia, "Toward Agile: An Integrated Analysis of Quantitative and Qualitative Field Data on Software Development Agility", MIS Quarterly 34(1), 2010, pp. 87. [29] Lindsjørn, Y., "Teamwork quality and project success in software development: A survey of agile development teams | Elsevier Enhanced Reader",

[30] Lindsjørn, Y., D.I. Sjøberg, T. Dingsøyr, G.R. Bergersen, and T. Dybla a, "Teamwork quality and project success in software development: A survey of agile development teams", Journal of Systems and Software 122, 2016, pp. 274-286.

[31] Marchand, D.A., and J. Peppard, "Why IT fumbles analytics", Harvard Business Review 91(1), 2013, pp. 104 112.

[32] Sheffield, J., and J. Lemétayer, "Factors associated with the software development agility of successful projects", International Journal of Project Management 31(3), 2013, pp. 459-472.

[33] Stankovic, D., V. Nikolic, M. Djordjevic, and D.-B. Cao, "A survey study of critical success factors in agile software projects in former Yugoslavia IT companies", Journal of Systems and Software 86(6), 2013, pp. 16631678.

[34] Strode, D., S. Huff, and A. Tretiakov, "The Impact of Organizational Culture on Agile Method Use.”, (2009), 1-9.

[35] Viaene, S., "The Secrets to Managing Business Analytics Projects", PROJECT MANAGEMENT, 2011, pp. 7. [36] Viaene, S., and A. Van den Bunder, "The secrets to managing business analytics projects", MIT Sloan Management Review 53(1), 2011, pp. 65.

[37] Vidgen, R., S. Shaw, and D.B. Grant, "Management challenges in creating value from business analytics",

European Journal of Operational Research 261(2), 2017, pp. 626-639.

[38] Wikum, E., "Making analytics work through practical project management", Analytics Magazine, 2016.

http://analytics-magazine.org/making-analytics-workthrough-practical-project-management/

[39] Yin, R.K., "Case Study Research", 2002.

[40] "Lee and Xia - 2010 - Toward Agile An Integrated Analysis of Quantitati.pdf",

http://www.cse.chalmers.se/ feldt/courses/agile/lee_2010_int egrated_analysis_of_sw_dev_agility.pdf 